Wright State University

CORE Scholar

2014

\title{
Why Is Living Fast Dangerous? Disentangling the Roles of Resistance and Tolerance of Disease
}

James P. Cronin

Megan A. Rúa

Wright State University - Main Campus, megan.rua@wright.edu

Charles E. Mitchell

Follow this and additional works at: https://corescholar.libraries.wright.edu/biology

Part of the Biology Commons, and the Systems Biology Commons

\section{Repository Citation}

Cronin, J. P., Rúa, M. A., \& Mitchell, C. E. (2014). Why Is Living Fast Dangerous? Disentangling the Roles of Resistance and Tolerance of Disease. The American Naturalist, 184 (2), 172-187.

https://corescholar.libraries.wright.edu/biology/628

This Article is brought to you for free and open access by the Biological Sciences at CORE Scholar. It has been accepted for inclusion in Biological Sciences Faculty Publications by an authorized administrator of CORE Scholar. For more information, please contact library-corescholar@wright.edu. 


\title{
Why Is Living Fast Dangerous? Disentangling the Roles of Resistance and Tolerance of Disease
}

\author{
James P. Cronin, ${ }^{1, \star}$ Megan A. Rúa, ${ }^{2, \dagger}$ and Charles E. Mitchell ${ }^{1,2}$ \\ 1. Department of Biology, University of North Carolina, Chapel Hill, North Carolina 27599; 2. Curriculum for the Environment and \\ Ecology, University of North Carolina, Chapel Hill, North Carolina 27599
}

Submitted July 15, 2013; Accepted January 28, 2014; Electronically published June 23, 2014

Online enhancement: appendixes. Dryad data: http://dx.doi.org/10.5061/dryad.8mq2q.

\begin{abstract}
Primary axes of host developmental tempo (HDT; e.g., slow-quick return continuum) represent latent biological processes and are increasingly used to a priori identify hosts that contribute disproportionately more to pathogen transmission. The influence of HDT on host contributions to transmission depends on how HDT influences both resistance and tolerance of disease. Here, we use structural equation modeling to address known limitations of conventional measures of resistance and tolerance. We first provide a general resistance-tolerance metamodel from which system-specific models can be derived. We then develop a model specific to a group of vector-transmitted viruses that infect hundreds of grass species worldwide. We tested the model using experimental inoculations of six phylogenetically paired grass species. We found that (1) host traits covaried according to a prominent HDT axis, the slow-quick continuum; (2) infection caused a greater reduction in the performance of quick returns, with $>80 \%$ of that greater impact explained by lesser resistance; (3) resistance-tolerance trade-off did not occur; and (4) phylogenetic control was necessary to measure the slow-quick continuum, resistance, and tolerance. These results support the conclusion that HDT's main influence on host contributions to transmission is via resistance. More broadly, this study provides a framework for quantifying HDT's influence on host contributions to transmission.
\end{abstract}

Keywords: pathogen reservoir, pathogen transmission, disease tolerance, disease resistance, host developmental tempo, structural equation modeling.

\section{Introduction}

In association with anthropogenic changes in ecosystem structures, many pathogens are being transmitted either at increased rates or to novel host species (e.g., Daszak et al. 2000; Anderson et al. 2004; Jones et al. 2008; Keesing et al. 2010). Consequently, a major research frontier is

\footnotetext{
* Corresponding author; e-mail: jpatrickrconin@gmail.com.

${ }^{\dagger}$ Present address: Department of Biology, University of Mississippi, University, Mississippi 38677.

Am. Nat. 2014. Vol. 184, pp. 172-187. (C) 2014 by The University of Chicago. 0003-0147/2014/18402-54825\$15.00. All rights reserved.

DOI: $10.1086 / 676854$
}

developing tools that allow a priori identification of hosts that have strong potential to contribute disproportionately more to transmission (Haydon et al. 2002; LoGiudice et al. 2003; Lloyd-Smith et al. 2005; Kilpatrick et al. 2006; Cronin et al. 2010b; Paull et al. 2012; Streicker et al. 2013). These hosts are generally expected to have greater values for key epidemiological parameters, namely, $(a)$ the probability of infection given exposure (susceptibility), $(b)$ the probability of transmitting a pathogen given contact (infectiousness), (c) fitness when infected, $(d)$ contact rates, and $(e)$ the ability to support larger vector and/or pathogen populations. Thus, research has focused on identifying suites of functional traits that simultaneously influence these epidemiological parameters (e.g., Cronin et al. 2010b; Johnson et al. 2012; Huang et al. 2013).

Specifically, attention has turned toward multidimensional functional trait axes, namely, the continuum of large- to small-body-size animals (e.g., Brown et al. 2004; Sibly and Brown 2007) and the continuum of slow- to quick-return plants (e.g., Wright et al. 2004; Cronin et al. $2010 b$ ). Compared to large-bodied animals, small-bodied animals often have shorter life spans and lower antibodybased adaptive immunity but greater metabolic, developmental, and reproduction rates (Sheldon and Verhulst 1996; Ricklefs and Wikelski 2002; Brown et al. 2004; Brown and Sibly 2006; Lee 2006; Lee et al. 2008; Johnson et al. 2012). Plants fall along a similar continuum based on traits of their leaves (Reich 2001; Enquist et al. 2007; Cronin et al. 2010b). For example, plants with long-lived, slow-growing, and high mass-per-unit-area leaves have low tissue nitrogen and phosphorus concentrations and metabolic rates (i.e., slow-return phenotypes). In contrast, plants with short-lived, fast-growing, and low mass-per-unit-area leaves have high tissue-nutrient concentrations and metabolic rates (i.e., quick-return phenotypes; e.g., Wright et al. 2004; Shipley et al. 2006; Cronin et al. 2010b). Lifehistory theories (e.g., $r / K$ selection, pace of life) attempt to explain why these and other traits predictably covary 
by invoking a variety of processes involving evolutionary and biophysical constraints and natural selection (e.g., Stearns 1992; Reich 2001; Brown et al. 2004; Dobson 2007). Here, we broadly refer to the latent process that causes correlations among functional traits as host developmental tempo (HDT; sensu Dobson 2007).

Because functional traits determine an organism's capacity to influence and respond to the environment, HDT increasingly provides the conceptual basis for ecological epidemiology (e.g., De Leo and Dobson 1996; Dobson 2004; Miller et al. 2007; Hall et al. 2008; Molnár et al. 2013). Small-bodied animal species have greater metabolic rates, which could cause greater microparasite replication rates and, therefore, more rapid disease progression compared to large-bodied animal species (Cable et al. 2007). Similarly, quick-return plants were more susceptible, more infectious, and supported larger vector- and virus-population sizes compared to slow-return plant phenotypes (Cronin et al. 2010b). In addition, amphibian species with small-bodied, fast-developing phenotypes were more susceptible to infection by trematodes and, subsequently, more likely to be malformed and die. These and other recent studies (e.g., Nunn et al. 2003; Todesco et al. 2010; van der Most et al. 2011; Duffy et al. 2012; Huang et al. 2013) suggest that large-bodied, slow-return phenotypes resist pathogen activity. As theoretical models predict that more-resistant phenotypes reduce pathogen transmission and prevalence (e.g., Roy and Kirchner 2000), the evidence suggests that small-bodied, quick-return hosts are less resistant and, thus, have greater potential to contribute to transmission.

Host developmental tempo, however, also has the potential to influence host contributions to transmission via host tolerance of disease. In contrast to resistant phenotypes, tolerant phenotypes do not reduce vector and/or pathogen activity. Instead, tolerant phenotypes have a greater capacity to acquire or allocate limiting resources when infected and, consequently, a greater capacity to minimize the impact of damage on host fitness (e.g., Chase et al. 2000b; Roy and Kirchner 2000; Stowe et al. 2000; Wise and Abrahamson 2005; Miller et al. 2007; Baucom and de Roode 2011; Medzhitov et al. 2012). By minimizing the impact of damage on host fitness, tolerant phenotypes might have the capacity to support greater vector and/or virus populations or remain infectious for a longer time period. In turn, such a capacity will increase the contribution of tolerant phenotypes to pathogen transmission and prevalence (Roy and Kirchner 2000; Miller et al. 2007; Hall et al. 2009; Cobb et al. 2010). Consequently, tolerance has the potential to counterbalance the influence of resistance on host contributions to transmission, which could prevent a general relationship between HDT and host contribution to transmission, depending on the re- lationship between tolerance and HDT. Specifically, if small-bodied, quick-return hosts are less resistant and less tolerant, then pathogen-induced morbidity and mortality will shorten their duration of infectiousness, limiting their potential to serve as reservoirs of pathogen transmission. In contrast, if small-bodied, quick-return hosts are less resistant but more tolerant, then they may shed pathogen propagules (or infect pathogen vectors) for an extended duration, increasing their potential to serve as reservoirs of pathogen transmission.

Despite the potential epidemiological importance of tolerance, the relationship between tolerance and HDT remains uncertain. While two recent empirical studies suggest that genetically determined tolerance decreases as HDT increases (Rose et al. 2009; Johnson et al. 2012), evolutionary models predict that tolerance can evolve to be greatest in large/slow phenotypes, small/quick phenotypes, or intermediate phenotypes (Stowe et al. 2000; Miller et al. 2007). Moreover, host tolerance is also strongly influenced by environmental conditions, particularly the availability of limiting resources (Wise and Abrahamson 2005; Hall et al. 2009; Cronin et al. 2010a), and this environmental influence could overwhelm genetic influences.

Furthermore, the effects of resistance and tolerance can be difficult to simultaneously disentangle in many systems (Chase et al. 2000a; Roy and Kirchner 2000; Miller et al. 2007), and this is particularly so for microparasites. Microparasites present a special challenge in this regard because they replicate extensively within host individuals (e.g., Råberg et al. 2007), thus linking resistance and tolerance and making them difficult to experimentally manipulate. While theoretical studies have emphasized the consequences of resistance, tolerance, and trade-offs between them (Chase et al. 2000b; Roy and Kirchner 2000; Miller et al. 2007), progress has been limited because conventional statistical methodologies inadequately measure host capacity to resist and tolerate microparasite infection. Primarily, univariate statistical models for resistance and tolerance cannot measure the relative contributions of resistance and tolerance when these defenses simultaneously determine the impact of infection on host fitness (app. A; apps. A-C are available online). Consequently, these models have limited utility, particularly for generalist microparasites, which cause significant problems for public health, agriculture, and conservation (e.g., Haydon et al. 2002; Anderson et al. 2004; Keesing et al. 2006). Because resistance and tolerance operate in concert in most systems, such models are not well suited to analyzing the impact of infection on host fitness, particularly for microparasite infections.

To overcome these challenges, we combined structural equation modeling (e.g., Grace et al. 2010, 2012) and ex- 
perimental inoculations of six grass host species grown across gradients of two resources. We began by developing a structural equation metamodel (SEMM) to map, at the most general level, relevant theoretical constructs and hypotheses regarding resistance and tolerance of infection. The SEMM provides a general theoretical model from which hypothesized causal models can be derived for any specific study system. We then used the SEMM to develop a causal model specific to barley and cereal yellow dwarf viruses (B/CYDVs), a group of vector-transmitted viral pathogens that infect hundreds of grass species worldwide (Irwin and Thresh 1990; D'Arcy 1995). As well as identifying hypotheses specific to our study system, the causal model operationalized the total influence of HDT on the impact of infection on host fitness and the relative contributions of resistance and tolerance to that total influence. It also allowed us to test for a trade-off between resistance and tolerance along HDT. Finally, we statistically tested our B/CYDV causal model against our experimental data using structural equation models (SEMs). Because evolutionary constraints shape HDT axes (Reich 2001; Dobson 2007) and shared host ancestry can influence epidemiological parameters (Gilbert and Webb 2007; Cronin et al. 2010b), we also tested whether controlling for shared ancestry of hosts was necessary to measure HDT, resistance, and tolerance.

\section{Mapping Theoretical Space: Development of the SEMM}

To map relevant theoretical space at the most general level, we developed a metamodel using the methodology outlined in Grace et al. (2010, 2012). Discussions about infection-induced changes in host fitness typically consider four general theoretical constructs: HDT, pathogen activity, limiting resource economics, and host fitness (e.g., De Leo and Dobson 1996; Roy and Kirchner 2000; Stowe et al. 2000; Dobson 2004; Cable et al. 2007; Miller et al. 2007; Cronin et al. 2010b; Johnson et al. 2012; Previtali et al. 2012; Huang et al. 2013). HDT is the primary developmental process that influences and causes correlations among functional traits, namely, physiological, structural, behavioral, and life-history traits. In turn, these traits simultaneously determine an organism's capacity to influence and respond to the environment, including host resistance and tolerance of pathogens. Pathogen activity is defined as any pathogen action that damages an infected host (e.g., consumption, replication). Limiting resource economics is defined as the feedback between the impact of infection on host acquisition of limiting resources $(\Delta \mathrm{ac}-$ quisition) and the impact of infection on host allocation of limiting resources ( $\Delta$ allocation). Finally, fitness is the impact of infection on host contributions to future generations ( $\Delta$ fitness).
Host developmental tempo may determine the impact of infection on host fitness via a variety of mechanisms important for determining infection-induced changes in host fitness (fig. 1a). By influencing functional traits and causing them to covary, HDT may influence an infected host's capacity to limit pathogen activity. In turn, pathogen activity influences $\Delta$ fitness when infected hosts experience loss of survival or offspring. Pathogen activity also influences $\Delta$ acquisition and $\Delta$ allocation when it creates or removes resource sources (e.g., removes apical dominance, alters foraging behavior) and/or resource sinks (e.g., damaged tissue, resource uptake by parasites). Host developmental tempo also affects $\Delta$ acquisition and $\Delta$ allocation by influencing functional traits and causing them to covary. Finally, $\Delta$ acquisition and $\Delta$ allocation influence $\Delta$ fitness because fitness can be resource limited, and consequently, the impacts of infection on resource limitation may influence host fitness. Resistance for a given system can be considered the net effect of the pathways from HDT to $\Delta$ fitness that are mediated by pathogen activity (fig. $1 a$ ). In contrast, tolerance can be considered the net effect of the pathways from HDT to $\Delta$ fitness that are mediated by resource economics, controlling for the influences of pathogen activity (fig. 1a). Importantly, the SEMM highlights that resistance and tolerance can simultaneously influence fitness via a shared set of resource economics.

In total, the SEMM provides a general theoretical map that is broadly applicable and could be developed with more conceptual detail (Grace et al. 2010, 2012). For example, models with reciprocal paths (i.e., nonrecursive models) imply a time series of events, where the variables indirectly influence themselves (Grace et al. 2007). Rather than model a time series (see Shipley 2000, fig. 2.22; Grace 2006, fig. 7.8), figure $1 a$ makes the simplifying assumption that feedback between resource acquisition and allocation has reached equilibrium.

\section{Integrating Theory and Data: Development of the Causal Model}

The SEMM guided the development of a causal resistancetolerance model for $\mathrm{B} / \mathrm{CYDV}$ infections (fig. 1b). The causal model shows observed variables from our experiments, which were related to the SEMM's theoretical constructs (defined in table 1), and hypothesized relationships among observed variables, which were based on knowledge about B/CYDV-host interactions and general knowledge about plant resource economics (defined in table 2). Note that the causal model emphasizes HDT's influence on pathogen activity and limiting resource economics, rather than the influence of specific functional traits. We advocate this framework as a general approach because multiple covarying traits (i.e., traits with shared variances), rather 


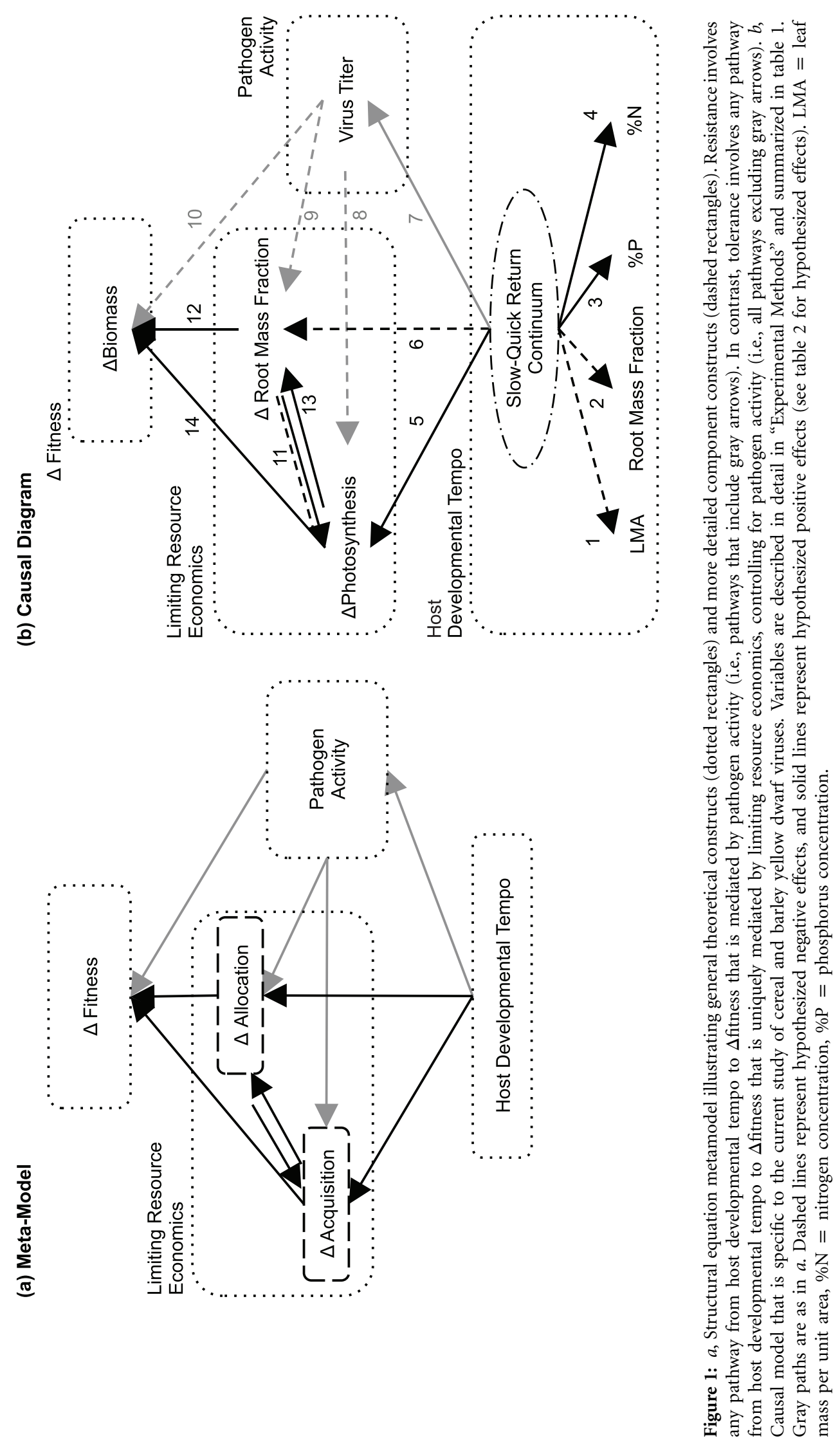

This content downloaded from 130.108.169.094 on December 18, 2017 11:42:34 AM

All use subject to University of Chicago Press Terms and Conditions (http://www.journals.uchicago.edu/t-and-c). 
Table 1: Theoretical constructs shown in the structural equation metamodel (fig. 1a) and observed variables related to those constructs and shown in the causal model (fig. $1 b$ )

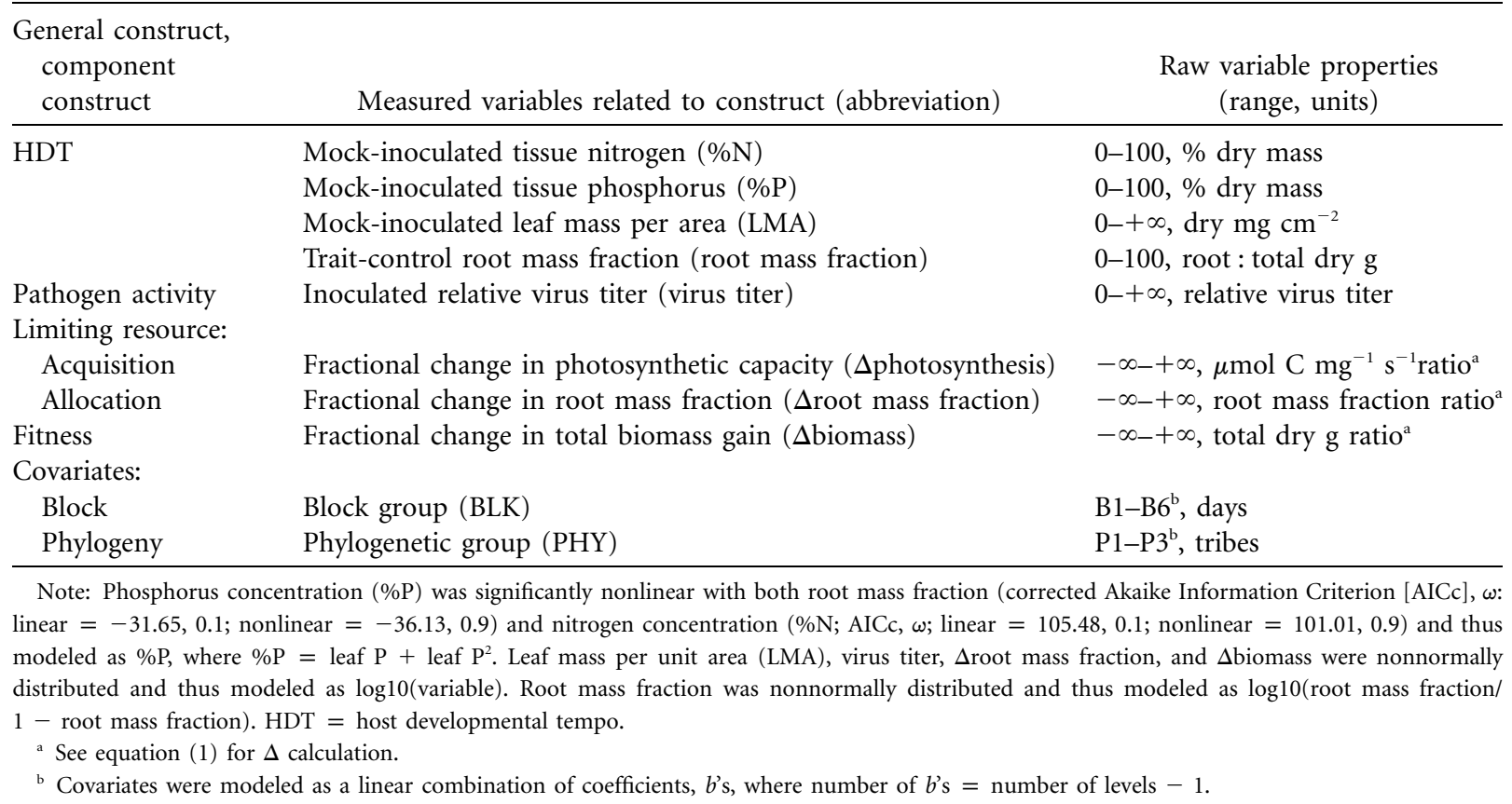

than single traits, influence epidemiological parameters (Cronin et al. 2010b). Moreover, the functional roles of specific traits in defense are often unknown, or if known, the roles are diverse or data are unavailable due to measurement costs (Chase et al. 2000a; Cornelissen et al. 2003).

Below, we reoperationalize conventional measures of resistance and tolerance, providing an improved mechanistic approach for investigations of the capacity of HDT to influence impacts of infection on host fitness. It is important to note that this reoperationalization and approach, while illustrated with one study system, applies broadly across host-pathogen systems.

Measuring the Impact of Infection on Host Fitness. Conventional univariate models propose to explain variation in the impact of infection on the absolute fitness of hosts, which allows only indirect inference about impacts on relative fitness (app. A). In contrast, our causal model (fig. $1 b$ ) proposes to explain variation in the impact of infection on the relative fitness of hosts (i.e., $\Delta$ fitness), which is more relevant to distinguishing among theoretical mechanisms (Chase et al. 2000a; Roy and Kirchner 2000). We quantified $\Delta$ fitness between paired inoculated $\left(I_{i}\right)$ and mock-inoculated $\left(M_{i}\right)$ hosts as the fractional change in total biomass due to infection:

$$
\Delta_{i}=\frac{I_{i}}{M_{i}} .
$$

This metric is directly relevant to dynamic ecological epidemiology models: it is the multiplier used to adjust the infected host's fitness relative to the uninfected host's fitness (e.g., Roy and Kirchner 2000; Borer et al. 2007), where $\Delta<1$ indicates that infection decreased biomass, while $\Delta>1$ indicates that infection increased biomass. Note that $\Delta$ photosynthesis and $\Delta$ root mass fraction were also calculated with equation (1), as these variables encompass different fitness components.

Measuring HDT's Total Influence, Resistance, Tolerance, and Trade-offs. Univariate models measure host resistance by estimating the coefficients relating damage (e.g., virus titer) to host genotype or phenotype (fig. A1; figs. A1, A2, and B2 are available online) and host tolerance by estimating the interactive effect of damage and either genotype or phenotype on absolute host fitness (fig. A1). In our approach, resistance and tolerance are measured by the indirect effects of HDT on $\Delta$ fitness, which can be calculated using standard path multiplication rules (Grace 2006). Specifically, resistance is the sum of all of HDT's indirect effects that are uniquely mediated by pathogen activity. In contrast, tolerance is the sum of all of HDT's indirect effects that are uniquely mediated by limiting resource economics. Consequently, the relative importance and trade-offs between resistance and tolerance can be quantified.

This novel feature of our modeling framework, which allows for the partitioning of resistance and tolerance, re- 
Table 2: Hypothesized mechanisms embodied by the causal diagram (fig. 1b)

\begin{tabular}{|c|c|c|c|}
\hline Driver, path & Response & $\begin{array}{c}\text { Predicted } \\
\text { correlation }\end{array}$ & Rationale for predicted relationship \\
\hline \multicolumn{4}{|l|}{ Slow-quick: } \\
\hline 1 & LMA & $<0$ & $\begin{array}{l}\text { Slow returns heavily invest in structure and resource storage, while } \\
\text { quick returns heavily invest in nutrient-rich metabolic machinery } \\
\text { (Poorter 1995; Wright et al. 2004; Shipley et al. 2006) }\end{array}$ \\
\hline 2 & Root mass fraction & $<0$ & See path 1 \\
\hline 3 & $\% \mathrm{P}$ & $>0$ & See path 1 \\
\hline 4 & $\% \mathrm{~N}$ & $>0$ & See path 1 \\
\hline 5 & $\Delta$ Photosynthesis & $>0$ & $\begin{array}{l}\text { Quick returns invest in metabolic machinery, enhancing capacity to } \\
\text { increase carbon acquisition (Strauss and Agrawal 1999; Stowe et al. } \\
\text { 2000) }\end{array}$ \\
\hline 6 & $\Delta$ Root mass fraction & $<0$ & $\begin{array}{l}\text { Slow returns invest in greater root stores and, thus, must reallocate a } \\
\text { smaller portion of root stores to overcome infection-induced re- } \\
\text { source limitation (Myers and Kitajima 2007; Imaji and Seiwa } \\
\text { 2010) }\end{array}$ \\
\hline 7 & Virus titer & $>0$ & $\begin{array}{l}\text { Slow returns have lower metabolic rates, lower nutrients, and/or } \\
\text { greater resistance defenses, which limit B/CYDV replication (Cro- } \\
\text { nin et al. } 2010 b \text { ) }\end{array}$ \\
\hline \multicolumn{4}{|l|}{ Virus titer: } \\
\hline 8 & $\Delta$ Photosynthesis & $<0$ & $\begin{array}{l}\text { Greater B/CYDV populations damage more phloem, which inhibits } \\
\text { photosynthetic pathways by decreasing chlorophyll content and } \\
\text { causing carbohydrate accumulation in leaves (Jensen and D'Arcy } \\
\text { 1995) }\end{array}$ \\
\hline 9 & $\Delta$ Root mass fraction & $<0$ & $\begin{array}{l}\text { Greater B/CYDV populations more strongly decrease carbon alloca- } \\
\text { tion to roots (Jensen and D'Arcy 1995) }\end{array}$ \\
\hline 10 & $\Delta$ Biomass & $<0$ & $\begin{array}{l}\text { Greater B/CYDV populations damage more phloem, which causes } \\
\text { greater leaf and root senescence (Jensen and D'Arcy 1995) }\end{array}$ \\
\hline \multicolumn{4}{|c|}{$\Delta$ Root mass fraction: } \\
\hline $11 \mathrm{a}$ & $\Delta$ Photosynthesis & $<0$ & $\begin{array}{l}\text { Infection shifts (re)allocation toward shoot growth, which supports } \\
\text { construction of photosynthetic tissue (Strauss and Agrawal 1999; } \\
\text { Stowe et al. 2000) }\end{array}$ \\
\hline $11 b$ & $\Delta$ Photosynthesis & $>0$ & $\begin{array}{l}\text { Infection shifts (re)allocation toward shoot growth, which decreases } \\
\text { the acquisition of soil resources necessary to support photosynthe- } \\
\text { sis (Haber 1995) }\end{array}$ \\
\hline 12 & $\Delta$ Biomass & $>0$ & $\begin{array}{l}\text { Infection shifts (re)allocation toward shoot growth, which decreases } \\
\text { the acquisition of soil resources that limit growth more than car- } \\
\text { bon (Poorter 1995) }\end{array}$ \\
\hline \multicolumn{4}{|c|}{$\Delta$ Photosynthesis: } \\
\hline 13 & $\Delta$ Root mass fraction & $>0$ & $\begin{array}{l}\text { Infection decreases carbon acquisition, which requires a greater per- } \\
\text { cent of root carbon stores to be reallocated to shoots (Myers and } \\
\text { Kitajima 2007) }\end{array}$ \\
\hline 14 & $\Delta$ Biomass & $>0$ & $\begin{array}{l}\text { Severe reductions in carbon acquisition increase carbon limitations } \\
\text { on growth (Myers and Kitajima 2007) }\end{array}$ \\
\hline
\end{tabular}

Note: Described are each path's driver, response, predicted correlation, and the rationale for that prediction. Note that $\Delta$ photosynthesis, $\Delta$ root mass fraction, and $\Delta$ biomass are ratios, where $\Delta<1($ or $\log 10(\Delta)<0)$ indicates that infection decreased the variable, and $\Delta>1($ or $\log 10(\Delta)>0)$ indicates that infection increased the variable (see eq. [1]). Driver and response definitions and units are as in table $1 . \mathrm{B} / \mathrm{CYDV}=$ barley and cereal yellow dwarf virus. $\mathrm{LMA}=$ leaf mass per unit area, $\% \mathrm{P}=$ phosphorus concentration, $\% \mathrm{~N}=$ nitrogen concentration.

quires calculation of indirect effects that can be quite complex when variables influence not only other variables but themselves as well. For example, the indirect effect of $x$ on $y_{2}$ in an example pathway, $x \rightarrow y_{1} \rightarrow y_{2}$, does not include a feedback loop and is simply the product of the path coefficients ( $b_{n}$; Grace 2006),

$$
b_{x y_{1}} \times b_{y_{1} y_{2}} .
$$

In contrast, calculating the indirect effect for a single pathway that involves a feedback loop must consider both the pathway's direction and the fact that the variables indirectly influence themselves (Grace 2006). For example, if 
there are reciprocal paths between $y_{1}$ and $y_{2}$, then the indirect effect of $x$ on $y_{2}$ is

$$
b_{x y_{1}} \times b_{y_{1} y_{2}} \times\left(\frac{1}{1-b_{y_{1} y_{2}} \times b_{y_{2} y_{1}}}\right),
$$

where $b_{x y 1}$ is the first path's coefficient, $b_{y 1 y 2}$ is the direct effect of the feedback loop, and the parenthetical term is the loop's indirect effect (Grace 2006). Utilizing equations (2) and (3) as guides, one can calculate HDT's indirect effects on $\Delta$ fitness and thus partition its total effect into measures of resistance and tolerance. Note that, in practice, this calculation should include only significant coefficient estimates from the final SEM, as this will reduce the potential for unreliable coefficient estimates. Resistance-tolerance trade-offs are evaluated by whether resistance and tolerance measures are of similar sign (no trade-off) or opposite sign (a trade-off). Finally, HDT's total influence on $\Delta$ fitness is the sum of resistance and tolerance, and the relative contributions of resistance or tolerance are calculated as fractions of HDT's total influence (Bollen 1989).

In total, evaluating the roles of resistance and tolerance and their trade-offs requires modeling them not as direct effects but as the sum of HDT's indirect effect on fitness. Moreover, the measures of both resistance and tolerance include any influence of limiting resource economics on host fitness. Consequently, replacing limiting resource economics with a direct path from HDT to host fitness conflates resistance and tolerance and thus does not allow accurate measurement of either. In contrast, our approach disentangles the roles of resistance and tolerance in host fitness, allowing them to be quantitatively partitioned.

\section{Experimental Methods}

We conducted the following experiment to illustrate the potential benefits of using SEM for examining the potential role of HDT in influencing infection-induced changes in host fitness.

\section{Study System}

Barley and cereal yellow dwarf viruses (B/CYDVs) are a group of phloem-limited, aphid-transmitted RNA viruses (family Luteoviridae) that infect hundreds of grass species worldwide (Irwin and Thresh 1990; D'Arcy 1995); the impact of infection fitness varies widely among hosts (e.g., Jensen and D'Arcy 1995; Malmström and Field 1997; Malmström et al. 2005; Seabloom et al. 2009). These viruses replicate only in hosts, and transmission among hosts occurs only by feeding aphids (Gray and Gildow 2003). Transmission between a feeding aphid and a host generally requires 2 h to 3 days (Gray et al. 1991; Power et al. 1991).
The virus can quickly spread in phloem, such that systemic infection can develop within hours of infection, and there is no documented recovery from infection (Jensen and D'Arcy 1995). The virus directly influences carbon acquisition and allocation by damaging phloem, which reduces chlorophyll content and carbohydrate translocation (Jensen and D'Arcy 1995). This decreases carbon acquisition, allocation of carbohydrates to roots, and leaf and root growth, while increasing leaf and root senescence (Jensen and D'Arcy 1995; Malmström and Field 1997).

In 2007, we obtained an isolate of barley yellow dwarf virus-PAV (BYDV-PAV) from a naturally infected wild Bromus vulgaris (Hook.) Shear individual in Andrews Experimental Forest, Blue River, Oregon. The virus was subsequently propagated in the Avena sativa cultivar Coast Black oats (CBO). We used Rhopalosiphum padi (L.) aphids, a common vector of B/CYDVs, from a single genotype collected in Ithaca, New York, and subsequently propagated parthenogenetically on Hordeum vulgare cultivars Lud and Steptoe. Rhopalosiphum padi efficiently transmits BYDV-PAV, including on the U.S. Pacific coast (Jensen and D'Arcy 1995; Seabloom et al. 2009). For our host species, we used six phylogenetically paired native perennial and exotic annual grasses (Aveneae = Avena fatua and Koeleria macrantha; Bromeae = Bromus hordeaceus and Bromus carinatus; and Triticeae = Taeniatherum caput-medusae and Elymus glaucus). Seed was collected from wild populations in Missouri (A. fatua) or California (the five remainder species).

\section{Experimental Design}

Between 2010 and 2011, we conducted a greenhouse experiment at the University of North Carolina, Chapel Hill. The experiment was a full-factorial manipulation of host species (six; see above), soil nitrogen (low, high), soil phosphorus (low, high), and infection status (paired mockinoculated and inoculated hosts). The design also included a trait-control treatment, which was harvested on inoculation day to estimate mock-inoculated and inoculated biomass prior to infection. The design was blocked by data collection day (6 days) and, except for trait controls, harvested 4 weeks postinoculation to allow for virus and host growth to equilibrate.

\section{Establishment and Maintenance}

Soil Resources. We grew $88-112$ genetically diverse individuals per grass species in 938-mL D60 Deepots (Stuewe and Sons, Tangent, OR) filled with soil mixed by volume at a $1.5: 1$ ratio of sterilized sand to potting soil (Sunshine LC-1, Sun Gro Horticulture, Vancouver, British Columbia), $0.039 \mathrm{~g}$ of pulverized $\mathrm{K}_{2} \mathrm{SO}_{4}$, and $0.39 \mathrm{~g}$ of micro- 
nutrients (Micromax, Scott, Marysville, OH). Soil phosphorus-either $0.0119 \pm 0.0021 \mathrm{~g}$ or $0.1975 \pm 0.0099 \mathrm{~g}$ of pulverized Triple Super Phosphate (Espoma, Millvale, $\mathrm{NJ}$ )—was mixed into each pot's top $5 \mathrm{~cm}$ of soil. For soil nitrogen, individual pots received a total of either 0.0055 $\mathrm{g}$ or $0.11 \mathrm{~g}$ of $\mathrm{NH}_{4} \mathrm{NO}_{3}$, added across 6 weeks as $5 \mathrm{~mL}$ of either $0.002-\mathrm{M}$ or $0.039-\mathrm{M}$ solution. We chose soil nitrogen and phosphorus because they can be limiting resources in this system (Seabloom et al. 2003; Dukes and Shaw 2007; Borer et al. 2010; Cronin et al. 2010b). The nutrient rates and ratios were similar to large-scale field experiments in this study system (Borer et al. 2010; Lind et al. 2013). At the one-leaf stage, pots were thinned to a single individual by removing short and tall individuals relative to the species' average height.

Experimental Inoculations. For each nutrient treatment combination, we randomly assigned 6 pots per species to a trait-control group, 6 pots per species to a mock-inoculated group, and 9-12 pots per species to an inoculated group. We chose a larger inoculated sample size for some species because previous research demonstrated low probabilities of infection for those species (Cronin et al. 2010b). Hosts in the trait-control group were treated with no aphids, hosts in the mock-inoculated group were treated with uninfected aphids, and hosts in the inoculated group were treated with infected aphids. Aphids were infected by feeding on BYDV-PAV-infected A. sativa cultivar CBO tissue for $48 \mathrm{~h}$, while uninfected aphids fed on uninfected $\mathrm{CBO}$ tissue for $48 \mathrm{~h}$. Five uninfected adult aphids were then caged on each mock-inoculated host, and five newly infected adult aphids were caged on each inoculated host. After 3 days, aphids were removed with horticultural oil (Saf-T-Side, ClawEl, Pleasant Plains, IL).

Response Variables. Trait-control hosts were separated into shoots and roots. The roots were stored at $-4^{\circ} \mathrm{C}$ until rinsed of soil using water and a fine-mesh screen, dried, and weighed. Trait-control root mass fraction (hereafter, root mass fraction) was calculated as root dry mass (g)/ total dry mass $(\mathrm{g})$. On each mock-inoculated and inoculated host, photosynthetic capacity (i.e., $A_{\max } ; \mu \mathrm{mol} \mathrm{CO}_{2}$ $\mathrm{mg}^{-1} \mathrm{~s}^{-1}$ ) was measured on the youngest, fully mature leaf of a haphazardly selected ramet using a CIRAS-2 gas exchange analyzer fitted with a rice cuvette (PP Systems, Amesbury, MA). To quantify leaf mass per unit area (LMA), the photosynthesis leaf was harvested, digitally scanned for leaf area (WinFOLIA, Regent Instruments, Canada), dried, and weighed. The plant was separated into roots and shoots. Roots were stored at $-4^{\circ} \mathrm{C}$ until rinsed of soil using water and a fine-mesh screen, dried, and weighed. Shoots were finely cut, mixed, and divided into nutrient and virus samples. Nutrient samples were weighed wet, dried, reweighed, and analyzed for nitrogen $(\% \mathrm{~N})$ and phosphorus $(\% \mathrm{P})$ concentrations, using, respectively, a micro-Dumas combustion analysis or dry ash/acid extraction (Analytical Chemistry Laboratory, Odum School of Ecology, University of Georgia, Athens).

Virus samples for both mock-inoculated and inoculated hosts were immediately weighed wet and analyzed for both host infection status and virus titer using a compound double-antibody sandwich enzyme-linked immunosorbent assay (DAS-ELISA; Agdia, Elkhart, IN). These DASELISA samples were prepared at a $1: 10$ ratio of virus sample dry weight (g) to phosphate-buffered saline volume $(\mu \mathrm{L})$. Host infection status was determined from the samples' optical density values corrected for variation caused by compounds present in healthy plant sap. (Optical density values are the raw data yielded by ELISA, when the concentration of the product of the enzymatic reaction is determined on a microplate reader.) Relative virus titer was estimated for infected hosts from DAS-ELISA samples using the following standard curve protocol: preliminary experiments suggested that optical density values are indistinguishable among samples with high virus titers because antibody sites become saturated (i.e., relationships of optical density on known virus titer plateau at high virus titer; M. G. Dekkers, J. P. Cronin, and C. E. Mitchell, unpublished data). Therefore, two DAS-ELISA samples per infected host were loaded on separate microplates at a $1: 10$ dilution ratio of DAS-ELISA sample to healthy tissue extract of the same species. Each plate also included a dilution series of infected $\mathrm{CBO}$ tissue to provide platespecific standard curves.

Bivariate inspections of $\mathrm{CBO}$ dilution series revealed nonlinear standard curves for each microplate (fig. B1). Therefore, likelihood ratio tests were used to select a nonlinear least squares model with the stats package and nls function of $\mathrm{R}$, version 3.0.1 (R Development Core Team 2013; table B1; tables A1-A4, B1, and C1-C4 are available online), which predicted viral titer of inoculated, ELISAconfirmed infected hosts (fig. B1). Because the ELISA samples were diluted by a factor of 10 and because there were two replicates per host, we calculated each host's average relative virus titer (hereafter, virus titer) as

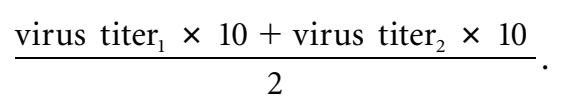

Three hosts had a sample optical density value that exceeded the standard curve's minimum or maximum virus titer (fig. B1). These were assigned the standard curve's minimum or maximum relative titer prior to calculating virus titer.

Because tissue allocated to ELISA is destroyed during the ELISA process, virus sample dry weights were estimated as 
(a) Full Structural Equation Model

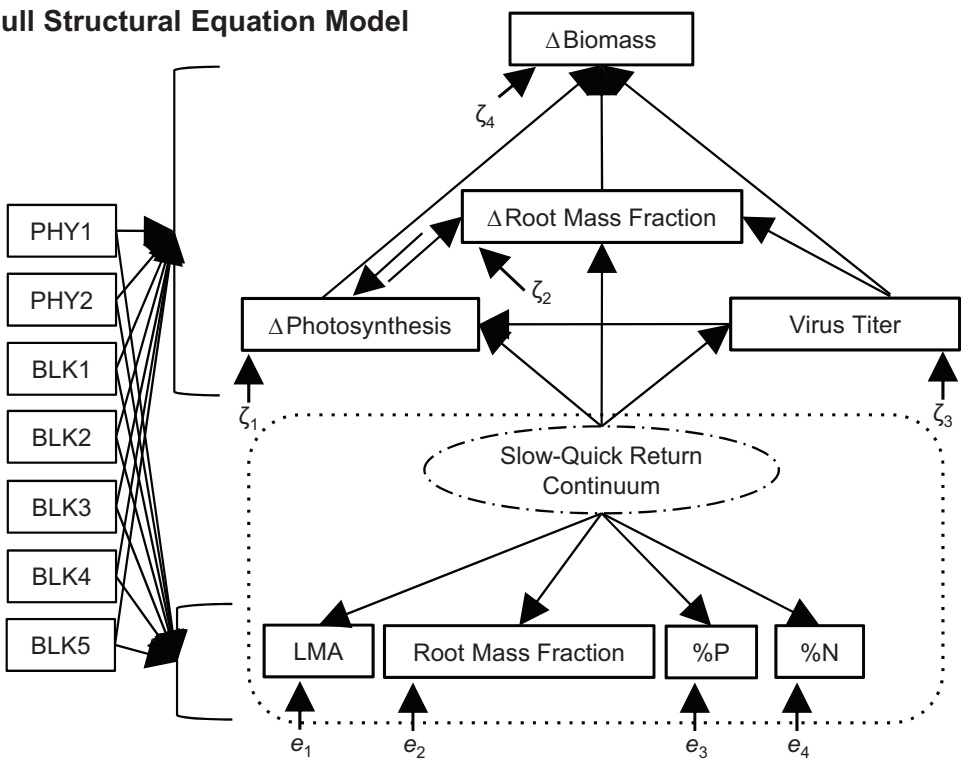

(b) Final Confirmatory Factor Analysis Results

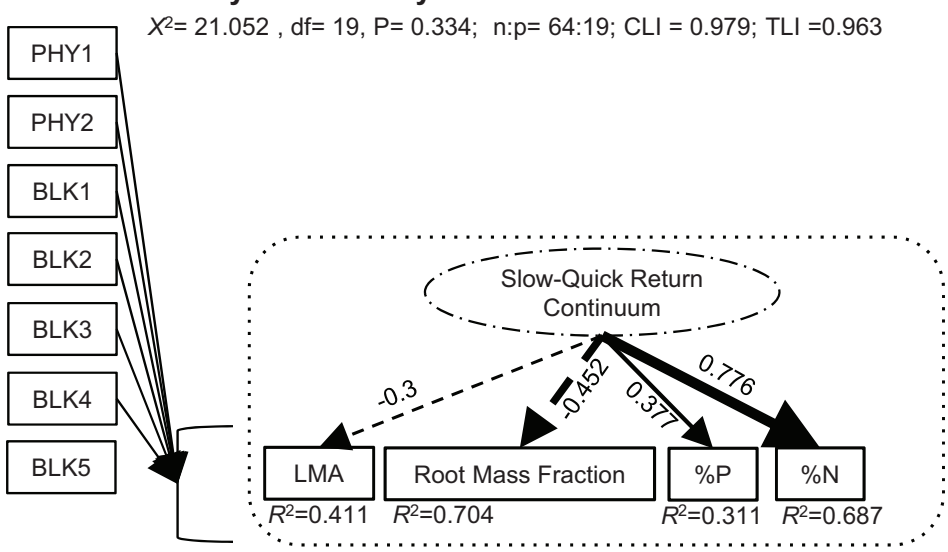

(c) Final Structural Equation Model Results

$X^{2}=57.111, \mathrm{df}=56, \mathrm{P}=0.434 ; \mathrm{n}: \mathrm{p}=64: 36 ; \mathrm{CLI}=0.995 ; \mathrm{TLI}=0.993$

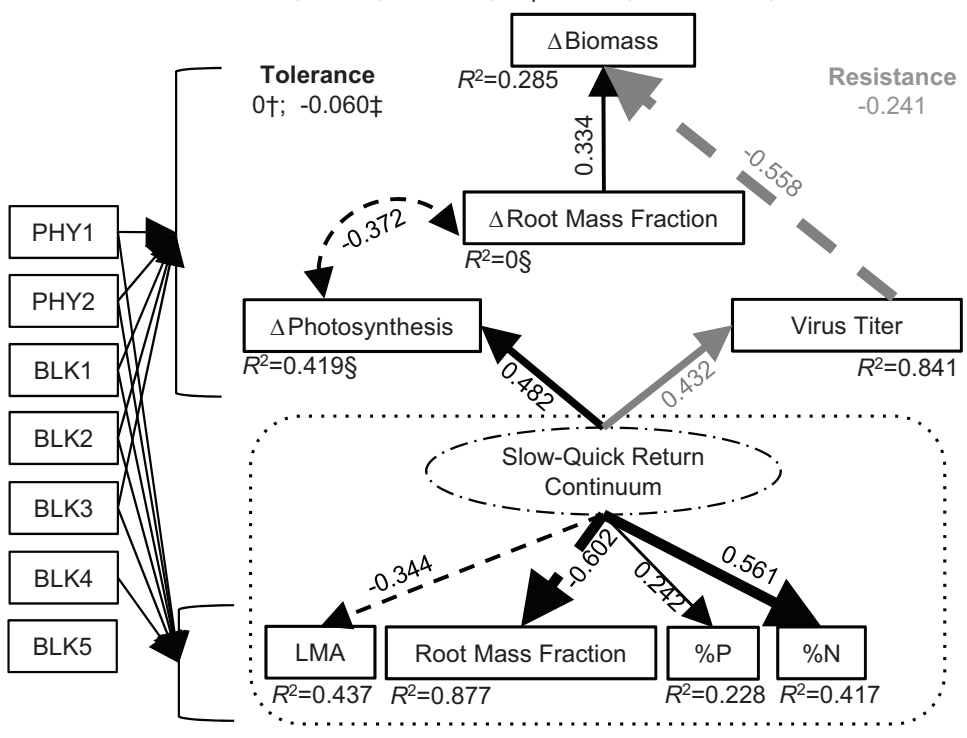

This content downloaded from 130.108.169.094 on December 18, 2017 11:42:34 AM All use subject to University of Chicago Press Terms and Conditions (http://www.journals.uchicago.edu/t-and-c). 
the product of virus sample wet mass and nutrient sample percent dry mass. Shoot dry mass (g) and root dry mass (g) for mock-inoculated and inoculated hosts were corrected by subtracting the mass of the paired trait control host. Subtracting trait-control biomass allowed us to quantify changes in biomass postinoculation, as the trait controls were harvested when the other plants were (mock) inoculated. We then calculated $\Delta$ photosynthesis, $\Delta$ root mass fraction, and $\Delta$ biomass using equation (1).

\section{Statistical Analyses}

Statistical analyses were conducted in $\mathrm{R}$, version 3.0.1 ( $\mathrm{R}$ Development Core Team 2013). We inspected bivariate relationships for nonlinearity and, where necessary, transformed data to normalize distributions prior to analysis (table A1). After accounting for missing data, inoculated hosts that remained uninfected, and preinoculation mortality (mock-inoculated hosts: one Koeleria macrantha; inoculated hosts: two K. macrantha), there were 64 complete sets of hosts (i.e., units of analysis). Each set of hosts included one inoculated ELISA-confirmed infected host, one mock-inoculated ELISA-confirmed uninfected host, and one trait-control host.

Confirmatory Factor Analysis and Structural Equation Model. The causal model (fig. $1 b$ ) was statistically tested using a latent variable SEM modified to control for the experimental covariates of block and phylogenetic group (fig. 2a). These covariates were modeled as a linear combination of coefficients, where the number of coefficients equals the number of levels minus 1.

Latent variable SEMs have a measurement model portion, which here specified the latent slow-quick continuum variable, and a structural portion, which here specified the influences of the latent slow-quick continuum variable on pathogen activity, limiting resource economics, and fitness (fig. $2 a$; Bollen 1989). To reduce the potential for a poor measurement model fit contributing to poor SEM fit (Bol- len 1989), the measurement model was independently tested with a confirmatory factor analysis with the lavann package and cfa function (Rosseel 2012). The latent slowquick return continuum was considered well measured if the confirmatory factor analysis (CFA) was a statistically good fit to the data ( $\chi^{2}$ s $P>.05$, comparative fit index [CLI] and Tucker-Lewis index [TLI] $>0.9)$ and the coefficient significances $(P<.05)$ and estimates supported the predictions for paths $1-4$ in table 2. Inspection of the CFA's coefficients revealed 17 highly nonsignificant covariate coefficients (i.e., block or phylogeny covariance $Z$ score $P>.1$; table $\mathrm{C} 1)$. We therefore reduced the model: highly nonsignificant coefficients were constrained to zero, and the CFA was refit. Likelihood ratio tests, coefficient comparisons, and multivariate $R^{2}$ comparisons of the full CFA and reduced CFA confirmed that the 17 highly nonsignificant covariate coefficients did not significantly contribute to model fit (tables C3, C4). Thus, the reduced CFA is presented in "Results" as the final CFA.

The full SEM, which included both the measurement and structural portions, was then fit to the data with the lavann package and sem function of $\mathrm{R}$ (Rosseel 2012) using

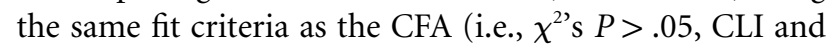
TLI $>0.9)$, and the SEM coefficient significances $(P<.05)$ and estimates were compared to the predictions in table 2. We were, however, unable to directly test the reciprocal paths because both $\Delta$ photosynthesis and $\Delta$ root mass fraction are influenced by the slow-quick return continuum, pathogen activity, and each other (fig. $2 a$ ). Therefore, they lacked unique influences, making the reciprocal coefficient estimates unreliable (Bollen 1989). This model identification problem can be resolved by introducing instrumental variables, which are strongly related to, and only to, their respective participant (Bollen 1989, 2012). We lacked instrumental variables, and thus, the reciprocal paths were modeled as a residual error correlation between $\Delta$ root mass fraction and $\Delta$ photosynthesis. Consequently, the coefficients for the underlying paths were not estimated. Thus, in the event that the residual error corre-

Figure 2: Structural equation model (SEM) and results. $a$, Full SEM. Solid rectangles are observed variables, and the dot-and-dashed oval is a latent variable, where the large, dotted rectangle includes the measurement portion but excludes the structural portion. Residual error variances $(\zeta)$ and measurement error variances $(e)$ are indicated. For illustrative purposes, experimental covariate (PHY1, PHY2; BLK1BLK5) influences on observed variables are summarized with brackets. The reciprocal paths were not modeled because $\Delta$ photosynthesis and $\Delta$ root mass fraction lacked unique influences. $b$, Final confirmatory factor analysis (CFA) results. Model fit is reported above the diagram; path size and values are standardized coefficients. $c$, Final SEM results. Symbols are as in $b$, except the double-headed, curved arrow is the residual error correlation, which replaced the reciprocal paths. The magnitudes of resistance (gray) and tolerance (black) were calculated using equation (2) in the main text. Minimum (dagger) and maximum (double dagger) magnitudes and minimum $R^{2}$ (section sign) occur because the residual error correlation is not causal (see "Statistical Analyses"). The CFA and SEM coefficient tests are reported in tables C2 and C3, respectively. Those CFAs and SEMs without phylogenetic control did not fit the data (tables C3, C4). Data underlying figure 2 are deposited in the Dryad Digital Repository: http://dx.doi.org/10.5061/dryad.8mq2q (Cronin et al. 2014). Abbreviations are as in table 1 , with PHY $=$ phylogeny, BLK $=$ block, CLI $=$ comparative fit index, TLI $=$ Tucker-Lewis index, and $n: p=$ ratio of sample size to free parameters. 
lation between $\Delta$ root mass fraction and $\Delta$ photosynthesis was significant in our model, whether $\Delta$ photosynthesis $\rightarrow$ $\Delta$ root mass fraction, $\Delta$ root mass fraction $\rightarrow \Delta$ photosynthesis, or both paths are significant remained ambiguous. Indirect effects were calculated using the standard path multiplication rules as in equation (2), using standardized coefficients and both with and without the residual error correlation between $\Delta$ root mass fraction and $\Delta$ photosynthesis. This is justified because, despite the ambiguity of the underlying paths, the residual error correlation quantifies the net effect of the processes influencing the residual error correlation (Bollen 1989), and its inclusion versus exclusion provided maximum and minimum effect estimates. Finally, because correlations do not model causal influences, the residual error correlation does not contribute to multiple squared correlations $\left(R^{2}\right)$ for $\Delta$ root mass fraction and $\Delta$ photosynthesis. Consequently, $R^{2}$ reported in figure $2 c$ for $\Delta$ root mass fraction and $\Delta$ photosynthesis are minimum $R^{2}$. In the spirit of guiding future research, note that nonrecursive models may estimate negative $R^{2}$ for loop variables. Negative $R^{2}$, however, are not prima facie evidence for model rejection. Instead, negative $R^{2}$ indicate either a modeling problem or an incorrectly calculated $R^{2}$, which can be adjusted (Hayduk 2006).

Finally, the full SEM's free parameters $(p)$ exceeded the sample size $(n ; n: p=64: 77)$, which allowed SEM fit and parameter estimation but was undesirable. Inspection of the full SEM's coefficients revealed 38 highly nonsignificant covariate coefficients and four highly nonsignificant structural coefficients (table C2). We therefore reduced the number of free parameters using the CFA model selection procedure described above, except that four nested SEMs were compared: the full SEM $(n: p=64: 77)$, a covariate coefficient reduced SEM ( $n: p=64: 39)$, a structural coefficient reduced SEM $(n: p=64: 73)$, and a covariate and structural coefficient reduced SEM $(n: p=64: 35)$. The three reduced models did not significantly differ from the full SEM (tables C3, C4). Therefore, the covariate and structural coefficient reduced model is presented in the "Results" as the final SEM. To test the role of shared host ancestry, we reconducted the model selection procedure but excluded phylogenetic coefficients (tables C3, C4).

\section{Results}

The final CFA, where all highly nonsignificant coefficients were constrained to zero, fit the data well (fig. $2 c$; tables $\mathrm{C} 3, \mathrm{C} 4)$ and showed that individuals with greater root mass fractions and LMA had lower tissue nitrogen and phosphorus concentrations (fig. 2b). This result supports the existence of the hypothesized latent slow-quick return continuum (table 2). Tissue nitrogen concentration had the largest standardized correlation with the latent slow-quick return continuum (fig. $2 b$ ), suggesting that it was a relatively better indicator compared to the other indicators. Those CFAs that did not account for phylogeny did not fit the data $\left(\chi^{2}=25.581\right.$, df $=18, P=.11, n: p=$ $64: 12$, CLI $=0.891$, TLI $=0.842$; tables C3, C4).

The final SEM, where all highly nonsignificant coefficients were constrained to zero, also fit the data well (fig. $2 c$; tables $\mathrm{C} 3, \mathrm{C} 4)$ and supported two pathways by which the latent slow-quick continuum potentially influenced the impact of infection on host biomass (fig. 2c). The first pathway involved the latent slow-quick continuum, virus titer, and $\Delta$ biomass. The second pathway involved the latent slow-quick continuum, $\Delta$ photosynthesis, $\Delta$ root mass fraction, and $\Delta$ biomass. Next, we evaluate these relationships (fig. 3) relative to the predictions (table 2).

For the first pathway, quick returns supported greater virus titer (fig. 3e). This supports the prediction that slow returns have a greater capacity to limit pathogen replication (table 2, path 7). Individuals with the lowest virus titer, which were slow-return phenotypes, had more than three times greater total biomass compared to paired uninfected individuals: the lowest titer hosts' predicted $\Delta$ biomass (i.e., fractional change in total dry mass) was $3.15 \pm 0.19$ SE $(P<.0001)$. Increasing virus titer caused increasingly severe reductions of total biomass: the highest titer hosts' predicted $\Delta$ biomass (i.e., fractional change in total dry mass) was $0.77 \pm 0.05 \mathrm{SE}(P<.0001$; e.g., see fig. $3 d$ ). This pathway supports the prediction that greater B/CYDV populations destroy more phloem, which causes greater senescence (table 2, path 10). Thus, the first pathway indicates that infected slow-return phenotypes are more resistant, and the standardized measure for this pathway was -0.241 (i.e., $0.43 \times-0.558$ in fig. $2 c$ ). Resistance, however, cannot explain why low-titer slow-return individuals had greater total biomass compared to paired uninfected individuals (fig. $3 d$ ).

For the second pathway, infected quick-return phenotypes experienced less severe reductions of photosynthetic capacity (fig. 3c). This result supports the prediction that infected quick returns have a greater capacity to maintain carbon acquisition due to greater allocation toward metabolic machinery (table 2, path 5 ). There was a significant negative correlation between $\Delta$ photosynthesis and $\Delta$ root mass fraction, such that reductions in photosynthetic capacity were associated with increased root mass fraction (fig. $3 b$ ). The significant correlation indicates that at least one reciprocal path is significant and negative. Which path(s) is (are) significant, however, cannot be determined without additional data (i.e., instrumental variables). Finally, hosts that increased allocation to roots also had greater total dry mass: lowest $\Delta$ root mass fraction hosts' predicted $\Delta$ biomass was $0.67 \pm$ 0.04 SE, $P<.001$; highest $\Delta$ root mass fraction hosts' predicted $\Delta$ biomass was $1.64 \pm 0.10 \mathrm{SE}, P<.001$ (e.g., see fig. $3 a$ ). 

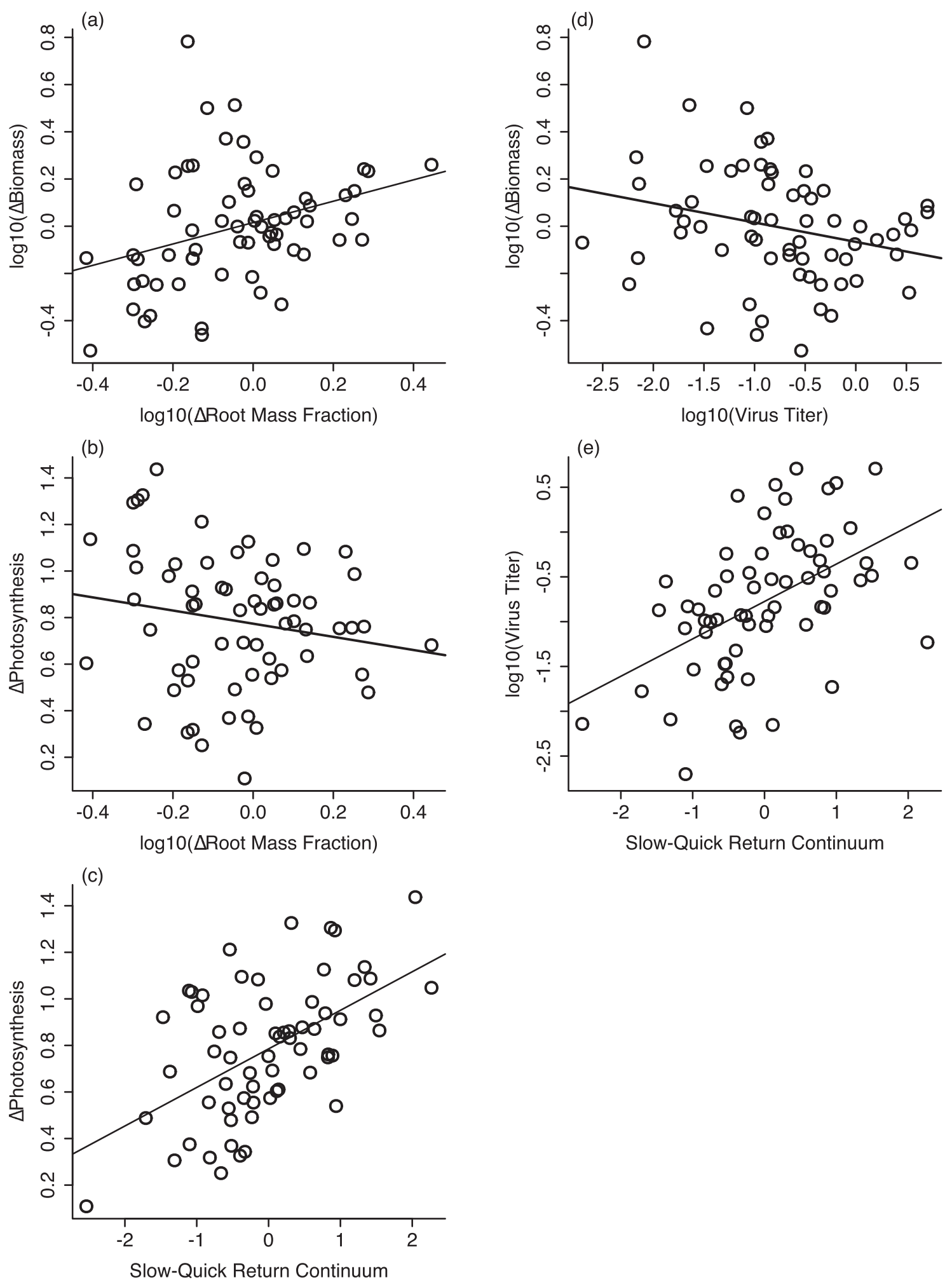

Figure 3: Bivariate relationships for significant structural equation model paths in fig. $2 c$. The relationship between $\Delta$ photosynthesis and $\Delta$ root mass fraction is a correlation and, therefore, should not be directionally interpreted. Note that $\Delta$ photosynthesis, $\Delta$ root mass fraction, and $\Delta$ biomass are ratios, where $\Delta<1$ or $\log 10(\Delta)<0$ indicates that infection decreased the variable, and $\Delta>1$ or $\log 10(\Delta)>0$ indicates that infection increased the variable (see eq. [1]). Data underlying figure 3 are deposited in the Dryad Digital Repository: http://dx.doi.org /10.5061/dryad.8mq2q (Cronin et al. 2014). 
This result supports the prediction that infected hosts were more limited by soil resources than by carbon, and consequently, increased allocation to roots supported greater biomass production (table 2, path 12). In total, the second pathway's results are ambiguous but may indicate that slow-return phenotypes were more tolerant. Because the slow-quick continuum may or may not have indirectly influenced $\Delta$ biomass via $\Delta$ photosynthesis, and the standardized measure for the tolerance pathway ranged from a maximum of -0.060 (i.e., $0.482 \times-0.372 \times 0.334$ in fig. $2 c$ ) to a minimum of 0 (i.e., $b_{\Delta \text { photosynthesis, } \Delta \text { root mass fraction }}=0$ ).

The above results showed that infected slow-return hosts had greater total biomass (fig. $3 d$ ), while infected quick-return phenotypes had a greater capacity to increase carbon acquisition (fig. 3c). However, measures for the resistance pathway and the tolerance pathway did not have opposite signs, indicating no resistance-tolerance trade-off.

Finally, the total influence of the latent slow-quick continuum on $\Delta$ biomass (i.e., the sum of resistance and tolerance) was negative and ranged from a minimum -0.241 to a maximum -0.301 . Thus, resistance accounted for $80 \%-100 \%$ of the slow-quick continuum's total influence. As with the CFA, SEMs that did not account for shared host ancestry poorly fit the data $\left(\chi^{2}=79.035, \mathrm{df}=53\right.$, $P=.012, n: p=64: 23$, CLI $=0.857$, TLI $=0.817$; tables C3, C4).

\section{Discussion}

This study reoperationalizes resistance and tolerance so that their measures are directly relevant to theory. In doing so, we address the limitations of univariate models that have stalled progress in host defense research, particularly in multihost, microparasite systems, which represent many infectious diseases causing substantial problems for public health, agriculture, and conservation (Haydon et al. 2002; Anderson et al. 2004; Keesing et al. 2006; Jones et al. 2008).

Our approach quantitatively partitions the effects of HDT on the relative fitness of infected hosts into resistance pathways and tolerance pathways. This has two major benefits over conventional approaches. First, it is more consistent with theory (fig. 1a) than approaches that model resistance and tolerance as direct effects (app. A). Second, it allows the roles of resistance and tolerance to be separately quantified and directly compared, whereas conventional approaches are unable to do this. Development of this framework reveals that approaches that model resistance and tolerance as direct effects may not provide adequate measures of resistance or tolerance because the measures are conflated. While we focused on resistance and tolerance in the context of host fitness, these defenses are expected to influence other epidemiological parameters
(Cronin et al. 2010b), so their analysis may benefit from a similar approach.

While the test of our causal model was limited in that we could not estimate the reciprocal path coefficients between resource acquisition and allocation, the results from our experiment showed that quick-return hosts experienced more severe impacts of infection on biomass, resistance explained $80 \%-100 \%$ of that total effect, and there was no resistance-tolerance trade-off. Quick returns were less resistant in that they supported greater virus populations, which decreased host biomass. Resistance, however, cannot explain why infected slow returns had greater final biomass compared to uninfected slow returns (fig. $3 d$ ). We also found that infected quick returns maintained relatively greater photosynthetic capacity and that infected hosts that maintained relatively larger root mass fractions maintained greater total mass. Our data, however, were not sufficient to fully resolve HDT's role in determining tolerance: we lacked instrumental variables and thus could not estimate the reciprocal feedback between $\Delta$ photosynthesis and $\Delta$ root mass fraction. Despite the ambiguous quantification of tolerance pathways, the experiment supports the conclusion that tolerance played a much lesser role than resistance in determining the impact of infection on host biomass. Moreover, our resistance and tolerance measures also did not detect a trade-off between resistance and tolerance: both resistance's measure and tolerance's maximum measure were negative, indicating that they decrease with HDT. This result supports Miller et al.'s (2007) adaptive dynamics model, which predicts that long-lived organisms evolve greater defenses, provided a particular resistance mechanism, acquired immunity, does not operate. Miller et al. (2007) predicted that under these conditions, which appear to operate in our study system, welldefended, longer-lived host populations have greater prevalence. Finally, models that did not account for phylogeny poorly fit the data, indicating that shared host ancestry plays a key role in shaping HDT's influence on epidemiological parameters.

Trade-offs between competitive ability, resistance, and tolerance are prominent mechanisms thought to influence ecological and evolutionary outcomes of consumerresource interactions (e.g., Chase et al. 2000a, 2000b; Roy and Kirchner 2000; Miller et al. 2007). In our system, these trade-offs are expected to explain why exotic annuals have invaded and now dominate California grasslands that were historically dominated by native perennials (Borer et al. 2007). Results presented here, in combination with previous work showing that native perennials are both slow returns and more resistant to both BYDV-PAV and its chief aphid vector (Cronin et al. 2010b), suggest that slow returns are better defended than quick returns. Additionally, the identification of native perennials as both slow returns 
(Cronin et al. 2010b) and as superior resource competitors (Seabloom et al. 2003) indicates that slow returns are better resource competitors than quick returns. Thus, added to these previous studies, our results suggest that there is not an HDT-driven resource competition-defense trade-off in our system. Detection of trade-offs involving resource competition, however, hinge on the identity of limiting resources. In the experiment presented here, variation along the slow-quick continuum was generated partly by using six host species and partly by manipulating the availability of two soil resources. In contrast, the primary impact of B/CYDVs on hosts is disruption of the uptake and distribution of a different resource-carbon from the atmosphere (Jensen and D'Arcy 1995; Malmström and Field 1997). Consequently, experiments that manipulate both $\mathrm{B} / \mathrm{CYDV}$ and light availability or the atmospheric concentration of $\mathrm{CO}_{2}$ might reveal both a greater importance of tolerance and a trade-off between tolerance and resistance (Wise and Abrahamson 2005; but see Rúa et al. 2013).

Previous empirical studies suggested that small/quick phenotypes are less resistant (e.g., Cable et al. 2007; Cronin et al. 2010b; Johnson et al. 2012; Huang et al. 2013), that large/slow phenotypes are more tolerant of infection (e.g., Rose et al. 2009; Johnson et al. 2012), and that accounting for shared host ancestry is critical for measuring HDT and its influence on epidemiological parameters (e.g., Cronin et al. 2010b; Huang et al. 2013). This is the first study, however, to measure the relative contributions of resistance and tolerance.

\section{Acknowledgments}

J.P.C. proposed and designed the models, designed and conducted the experiment, conducted the analyses, and wrote the manuscript. M.A.R. commented on the experimental design and manuscript, and conducted the experiment. C.E.M. designed the experiment and commented on the manuscript. We are grateful to F. Halliday and T. Pendergast for feedback on the SEMMs; to J. Grace, D. Schoolmaster, and C. Zimmer for advice on SEM specifications; and to the anonymous reviewers and C. Zimmer for critiques of the manuscript. M. Dekkers helped design and conduct the ELISAs. S. Power, J. Umbanhowar, and especially M. Welsh provided feedback on the experimental design. This research was funded by grants to C.E.M. from the National Science Foundation (NSF; DEB-0923671 and DEB-1015909). M.A.R. was supported by an NSF Graduate Research Fellowship and an NSF Postdoctoral Research Fellowship in Biology (DBI-1202676).

\section{Literature Cited}

Anderson, P. K., A. A. Cunningham, N. G. Patel, F. J. Morales, P. R. Epstein, and P. Daszak. 2004. Emerging infectious diseases of plants: pathogen pollution, climate change and agrotechnology drivers. Trends in Ecology and Evolution 19:535-544.

Baucom, R. S., and J. C. de Roode. 2011. Ecological immunology and tolerance in plants and animals. Functional Ecology 25:1828.

Bollen, K. A. 1989. Structural equations with latent variables. Wiley, New York.

- 2012. Instrumental variables in sociology and the social sciences. Annual Review of Sociology 38:37-72.

Borer, E. T., P. R. Hosseini, E. W. Seabloom, and A. P. Dobson. 2007. Pathogen-induced reversal of native dominance in a grassland community. Proceedings of the National Academy of Sciences of the USA 104:5473-5478.

Borer, E. T., E. W. Seabloom, C. E. Mitchell, and A. G. Power. 2010. Local context drives infection of grasses by vector-borne generalist viruses. Ecology Letters 13:810-818.

Brown, J. H., J. F. Gillooly, A. P. Allen, V. M. Savage, and G. B. West. 2004. Toward a metabolic theory of ecology. Ecology 85:17711789.

Brown, J. H., and R. M. Sibly. 2006. Life-history evolution under a production constraint. Proceedings of the National Academy of Sciences of the USA 103:17595-17599.

Cable, J. M., B. J. Enquist, and M. E. Moses. 2007. The allometry of host-pathogen interactions. PloS ONE 2:e1130.

Chase, J. M., M. A. Leibold, A. L. Downing, and J. B. Shurin. 2000a. The effects of productivity, herbivory, and plant species turnover in grassland food webs. Ecology 81:2485-2497.

Chase, J. M., M. A. Leibold, and E. Simms. 2000b. Plant tolerance and resistance in food webs: community-level predictions and evolutionary implications. Evolutionary Ecology 14:289-314.

Cobb, R. C., R. K. Meentemeyer, and D. M. Rizzo. 2010. Apparent competition in canopy trees determined by pathogen transmission rather than susceptibility. Ecology 91:327-333.

Cornelissen, J. H. C., S. Lavorel, E. Garnier, S. Díaz, N. Buchmann, D. E. Gurvich, P. B. Reich, et al. 2003. A handbook of protocols for standardised and easy measurement of plant functional traits worldwide. Australian Journal of Botany 51:335-380.

Cronin, J. P., M. A. Rúa, and C. E. Mitchell. 2014. Data from: Why is living fast dangerous? disentangling the roles of resistance and tolerance of disease. American Naturalist, Dryad Digital Repository, http://dx.doi.org/10.5061/dryad.8mq2q.

Cronin, J. P., S. J. Tonsor, and W. P. Carson. 2010a. A simultaneous test of trophic interaction models: which vegetation characteristic explains herbivore control over plant community mass? Ecology Letters 13:202-212.

Cronin, J. P., M. E. Welsh, M. G. Dekkers, S. T. Abercrombie, and C. E. Mitchell. 2010b. Host physiological phenotype explains pathogen reservoir potential. Ecology Letters 13:1221-1232.

D'Arcy, C. J. 1995. Symptomology and host range of barley yellow dwarf. Pages 9-28 in C. D’Arcy and P. Burnett, eds. Barley yellow dwarf: 40 years of progress. American Phytopathological Society, St. Paul, MN.

Daszak, P., A. A. Cunningham, and A. D. Hyatt. 2000. Emerging infectious diseases of wildlife: threats to biodiversity and human health. Science 287:443-449. 
De Leo, G. A., and A. P. Dobson. 1996. Allometry and simple epidemic models for microparasites. Nature 379:720-722.

Dobson, A. 2004. Population dynamics of pathogens with multiple host species. American Naturalist 164(suppl.):S64-S78.

Dobson, F. S. 2007. A lifestyle view of life-history evolution. Proceedings of the National Academy of Sciences of the USA 104: 17565-17566.

Duffy, M. A., J. H. Ochs, R. M. Penczykowski, D. J. Civitello, C. A. Klausmeier, and S. R. Hall. 2012. Ecological context influences epidemic size and parasite-driven evolution. Science 335:16361638.

Dukes, J. S., and M. R. Shaw. 2007. Responses to changing atmosphere and climate. Pages 218-229 in C. D'Antonio, J. D. Corbin, and M. Stromberg, eds. Ecology and management of California grasslands. University of California Press, Berkeley, CA.

Enquist, B. J., A. J. Kerkhoff, S. C. Stark, N. G. Swenson, M. C. McCarthy, and C. A. Price. 2007. A general integrative model for scaling plant growth, carbon flux, and functional trait spectra. Nature 449:218-222.

Gilbert, G. S., and C. O. Webb. 2007. Phylogenetic signal in plant pathogen-host range. Proceedings of the National Academy of Sciences of the USA 104:4979-4983.

Grace, J. B. 2006. Structural equation modeling and natural systems. Cambridge University Press, Cambridge.

Grace, J. B., T. M. Anderson, H. Olff, and S. M. Scheiner. 2010. On the specification of structural equation models for ecological systems. Ecological Monographs 80:67-87.

Grace, J. B., T. M. Anderson, M. D. Smith, E. Seabloom, S. J. Andelman, G. Meche, E. Weiher, et al. 2007. Does species diversity limit productivity in natural grassland communities? Ecology Letters 10: 680-689.

Grace, J. B., D. R. J. Schoolmaster, G. R. Guntenspergen, A. M. Little, B. R. Mitchell, K. M. Miller, and E. W. Schweiger. 2012. Guidelines for a graph-theoretic implementation of structural equation modeling. Ecosphere 3:1-44.

Gray, S., and F. E. Gildow. 2003. Luteovirus-aphid interactions. Annual Review of Phytopathology 41:539-566.

Gray, S. M., A. G. Power, D. M. Smith, A. J. Seaman, and N. S. Altman. 1991. Aphid transmission of barley yellow dwarf virus: acquisition periods and virus concentration requirements. Phytopathology 81:539-545.

Haber, S. 1995. Interactions of barley yellow dwarf viruses: cross protection and interactions with other pathogens and with abiotic factors. Pages 145-160 in C. D’Arcy and P. Burnett, eds. Barley yellow dwarf: 40 years of progress. American Phytopathological Society, St. Paul, MN.

Hall, S. R., K. D. Lafferty, J. H. Brown, C. E. Cáceres, J. M. Chase, A. P. Dobson, R. D. Holt, C. G. Jones, S. E. Randolph, and P. Rohani. 2008. Is infectious disease just another type of consumerresource interaction? Pages 223-241 in R. S. Ostfeld, F. Keesing, and V. T. Eviner, eds. Reciprocal interactions between ecosystems and disease. Princeton University Press, Princeton, NJ.

Hall, S. R., J. L. Simonis, R. M. Nisbet, A. J. Tessier, and C. E. Cáceres. 2009. Resource ecology of virulence in a planktonic host-parasite system: an explanation using dynamic energy budgets. American Naturalist 174:149-162.

Haydon, D. T., S. Cleaveland, L. H. Taylor, and M. K. Laurenson. 2002. Identifying reservoirs of infection: a conceptual and practical challenge. Emerging Infectious Diseases 8:1468-1473.

Hayduk, L. A. 2006. Blocked-error- $R^{2}$ : a conceptually improved def- inition of the proportion of explained variance in models containing loops or correlated residuals. Quality and Quantity 40:629649.

Huang, Z. Y. X., W. F. de Boer, F. van Langevelde, V. Olson, T. M. Blackburn, and H. H. T. Prins. 2013. Species' life-history traits explain interspecific variation in reservoir competence: a possible mechanism underlying the dilution effect. PloS ONE 8:e54341.

Imaji, A., and K. Seiwa. 2010. Carbon allocation to defense, storage, and growth in seedlings of two temperate broad-leaved tree species. Oecologia (Berlin) 162:273-281.

Irwin, M. E., and J. M. Thresh. 1990. Epidemiology of barley yellow dwarf: a study in ecological complexity. Annual Review of Phytopathology 28:393-424.

Jensen, S. G., and C. J. D'Arcy. 1995. Effects of barley yellow dwarf virus on host plants. Pages 55-74 in C. J. D'Arcy and P. A. Burnett, eds. Barley yellow dwarf: 40 years of progress. American Phytopathological Society, St. Paul, MN.

Johnson, P. T. J., J. R. Rohr, J. T. Hoverman, E. Kellermanns, J. Bowerman, and K. B. Lunde. 2012. Living fast and dying of infection: host life history drives interspecific variation in infection and disease risk. Ecology Letters 15:235-242.

Jones, K. E., N. G. Patel, M. A. Levy, A. Storeygard, D. Balk, J. L. Gittleman, and P. Daszak. 2008. Global trends in emerging infectious diseases. Nature 451:990-993.

Keesing, F., L. K. Belden, P. Daszak, A. Dobson, C. D. Harvell, R. D. Holt, P. Hudson, et al. 2010. Impacts of biodiversity on the emergence and transmission of infectious diseases. Nature 468:647652.

Keesing, F., R. D. Holt, and R. S. Ostfeld. 2006. Effects of species diversity on disease risk. Ecology Letters 9:485-498.

Kilpatrick, A. M., P. Daszak, M. J. Jones, P. P. Marra, and L. D. Kramer. 2006. Host heterogeneity dominates West Nile virus transmission. Proceedings of the Royal Society B: Biological Sciences 273:2327-2333.

Lee, K. A. 2006. Linking immune defenses and life history at the levels of the individual and the species. Integrative and Comparative Biology 46:1000-1015.

Lee, K. A., M. Wikelski, W. D. Robinson, T. R. Robinson, and K. C. Klasing. 2008. Constitutive immune defences correlate with lifehistory variables in tropical birds. Journal of Animal Ecology 77: 356-363.

Lind, E. M., E. Borer, E. Seabloom, P. Adler, J. D. Bakker, D. M. Blumenthal, M. Crawley, et al. 2013. Life-history constraints in grassland plant species: a growth-defence trade-off is the norm. Ecology Letters 16:513-521.

Lloyd-Smith, J. O., S. J. Schreiber, P. E. Kopp, and W. M. Getz. 2005. Superspreading and the effect of individual variation on disease emergence. Nature 438:355-359.

LoGiudice, K., R. S. Ostfeld, K. A. Schmidt, and F. Keesing. 2003. The ecology of infectious disease: effects of host diversity and community composition on Lyme disease risk. Proceedings of the National Academy of Sciences of the USA 100:567-571.

Malmström, C. M., and C. B. Field. 1997. Virus-induced differences in the response of oat plants to elevated carbon dioxide. Plant, Cell and Environment 20:178-188.

Malmström, C. M., C. C. Hughes, L. A. Newton, and C. J. Stoner. 2005. Virus infection in remnant native bunchgrasses from invaded California grasslands. New Phvtologist 168:217-230.

Medzhitov, R., D. S. Schneider, and M. P. Soares. 2012. Disease tolerance as a defense strategy. Science 335:936-941. 
Miller, M. R., A. White, and M. Boots. 2007. Host life span and the evolution of resistance characteristics. Evolution 61:2-14.

Molnár, P. K., S. J. Kutz, B. M. Hoar, and A. P. Dobson. 2013. Metabolic approaches to understanding climate change impacts on seasonal host-macroparasite dynamics. Ecology Letters 16:921.

Myers, J. A., and K. Kitajima. 2007. Carbohydrate storage enhances seedling shade and stress tolerance in a Neotropical forest. $\underline{\text { Journal }}$ of Ecology 95:383-395.

Nunn, C. L., J. L. Gittleman, and J. Antonovics. 2003. A comparative study of white blood cell counts and disease risk in carnivores. Proceedings of the Roval Society B: Biological Sciences 270:347356.

Paull, S. H., S. Song, K. M. McClure, L. C. Sackett, A. M. Kilpatrick, and P. T. Johnson. 2012. From superspreaders to disease hotspots: linking transmission across hosts and space. Frontiers in Ecology and the Environment 10:75-82.

Poorter, L. 1995. Resource capture and use by tropical forest tree seedlings and their consequences for competition. Pages 35-64 in D. Burslem, M. Pinard, and S. Hartley, eds. Biotic interactions in the tropics: their role in the maintenance of species diversity. Cambridge University Press, Cambridge.

Power, A. G., A. J. Seaman, and S. M. Gray. 1991. Aphid transmission of barley yellow dwarf virus: inoculation access periods and epidemiological implications. Phytopathology 81:545-548.

Previtali, M. A., R. S. Ostfeld, F. Keesing, A. E. Jolles, R. Hanselmann, and L. B. Martin. 2012. Relationship between pace of life and immune responses in wild rodents. Oikos 121:1483-1492.

R Development Core Team. 2013. R: a language and environment for statistical computing. R Foundation for Statistical Computing, Vienna.

Råberg, L., D. Sim, and A. F. Read. 2007. Disentangling genetic variation for resistance and tolerance to infectious diseases in animals. Science 318:812-814.

Reich, P. B. 2001. Body size, geometry, longevity and metabolism: do plant leaves behave like animal bodies? Trends in Ecology and Evolution 16:674-680.

Ricklefs, R. E., and M. Wikelski. 2002. The physiology/life-history nexus. Trends in Ecology and Evolution 17:462-468.

Rose, K. E., R. L. Atkinson, L. A. Turnbull, and M. Rees. 2009. The costs and benefits of fast living. Ecology Letters 12:1379-1384.

Rosseel, Y. 2012. lavaan: an R package for structural equation. Iournal of Statistical Software 48:1-36.

Roy, B. A., and J. W. Kirchner. 2000. Evolutionary dynamics of pathogen resistance and tolerance. Evolution 54:51-63.

Rúa, M. A., J. Umbanhowar, S. Hu, K. O. Burkey, and C. E. Mitchell. 2013. Elevated $\mathrm{CO}_{2}$ spurs reciprocal positive effects between a plant virus and an arbuscular mycorrhizal fungus. New Phytologist 199: 541-549.
Seabloom, E. W., E. T. Borer, A. Jolles, and C. E. Mitchell. 2009. Direct and indirect effects of viral pathogens and the environment on invasive grass fecundity in Pacific coast grasslands. Journal of Ecology 97:1264-1273.

Seabloom, E. W., W. S. Harpole, O. J. Reichman, and D. Tilman. 2003. Invasion, competitive dominance, and resource use by exotic and native California grassland species. Proceedings of the National Academv of Sciences of the USA 100:13384-13389.

Sheldon, B. C., and S. Verhulst. 1996. Ecological immunology: costly parasite defenses and trade-offs in evolutionary ecology. Trends in Ecology and Evolution 5347:317-321.

Shipley, B. 2000. Cause and correlation in biology: a user's guide to path analysis, structural equations, and causal inference. Cambridge University Press, Cambridge.

Shipley, B., M. J. Lechowicz, I. Wright, and P. B. Reich. 2006. Fundamental trade-offs generating the worldwide leaf economics spectrum. Ecology 87:535-541.

Sibly, R. M., and J. H. Brown. 2007. Effects of body size and lifestyle on evolution of mammal life histories. Proceedings of the National Academy of Sciences of the USA 104:17707-17712.

Stearns, S. C. 1992. The evolution of life histories. Oxford University Press, Oxford.

Stowe, K. A., R. J. Marquis, C. G. Hochwender, and E. L. Simms. 2000. The evolutionary ecology of tolerance. Annual Review of Ecology and Systematics 31:565-595.

Strauss, S., and A. Agrawal. 1999. The ecology and evolution of plant tolerance to herbivory. Trends in Ecology and Evolution 14:179185.

Streicker, D. G., A. Frenton, and A. B. Pedersen. 2013. Differential sources of host species heterogeneity influence the transmission and control of multihost parasites. Ecology Letters 16:975-984.

Todesco, M., S. Balasubramanian, T. T. Hu, M. B. Traw, M. Horton, P. Epple, C. Kuhns, et al. 2010. Natural allelic variation underlying a major fitness trade-off in Arabidopsis thaliana. Nature 465:632636.

van der Most, P. J., B. de Jong, H. K. Parmentier, and S. Verhulst. 2011. Trade-off between growth and immune function: a metaanalysis of selection experiments. Functional Ecology 25:74-80.

Wise, M. J., and W. G. Abrahamson. 2005. Beyond the compensatory continuum: environmental resource levels and plant tolerance of herbivory. Oikos 109:417-428.

Wright, I. J., P. B. Reich, M. Westoby, D. D. Ackerly, Z. Baruch, F. Bongers, J. Cavender-Bares, et al. 2004. The worldwide leaf economics spectrum. Nature 428:821-827.

Associate Editor: John J. Stachowicz Editor: Susan Kalisz 